Revista Española de Antropología Americana ISSN: 0556-6533

http://dx.doi.org/10.5209/reaa.70379

\title{
Indigeneidad performada. Apuntes etnográficos de dos festivales de cine indígena en Colombia y Panamá
}

\author{
Sebastián Gómez Ruiz ${ }^{1}$ y Gabriel Izard Martínez²
}

Recibido: 2 de julio de 2020 / Aceptado: 1 de septiembre de 2020

Resumen. El objetivo de este artículo es contribuir al análisis del cine indígena haciendo énfasis en su circulación y consumo en los festivales indígenas. Para ello partimos de un estudio etnográfico de dos festivales celebrados en 2018 (Daupará en Colombia y Jumara en Panamá), centrado en cómo se performa lo indígena en estos eventos. Lo que trataremos de argumentar es que una etnografía de los festivales indígenas nos permite acercarnos a unas puestas en escena que muestran cómo se está configurando lo indígena en la actualidad. Sugerimos que estos festivales tienen tres dimensiones: 1) constituyen una performance de lo indígena a través del cuerpo y la palabra, 2) revelan unas formas de organización interna que muestran un tejido social y político relacionado con linajes y liderazgos al interior de los grupos que organizan los festivales, y 3 ) permiten entender cómo se configura lo indígena no sólo en relación con los propios territorios concretos de cada grupo, sino también a partir de unos intercambios y unas agendas políticas locales y globales.

Palabras clave: cine indígena; festivales de cine; performance; indigeneidad.

\section{[en] Performed Indigeneity. Ethnographic Notes from Two Indigenous Film Festivals in Colombia and Panama}

\begin{abstract}
The objective of this article is to contribute to the analysis of indigenous cinema emphasizing on its circulation and consumption in indigenous film festivals. An ethnographic study of two festivals held in 2018 (Daupará in Colombia and Jumara in Panama) was carried out in order to observe how indigeneity is performed in these events. We argue that these kind of festivals may be considered as rich scenarios where indigeneity is being configured and understood in current times. Three dimensions of indigenous film festivals are suggested: 1) they constitute a performance of indigeneity through the body and the word, 2) they reveal social and political structures within the organizers of such festivals based on lineage and leaderships, and 3) they allow us to understand how indigeneity is configured not only in relation to specific territories of each group, but also through exchanges and local and global political agendas.
\end{abstract}

Keywords: indigenous cinema; film festivals; performance; indigeneity.

Sumario: 1. Introducción. 2. Artefactos culturales, cosmopolítica y puesta en escena. 3. Daupará y Jumara: la puesta en escena de la palabra y el cuerpo. 4. A manera de conclusión. 5. Referencias.

\footnotetext{
Universidad de El Bosque. gomezruiz1203@gmail.com.

$2 \quad$ Universidad de Barcelona. gabrielizard@ub.edu.
} 
Cómo citar: Gómez Ruiz, Sebastián y Gabriel Izard Martínez. "Indigeneidad performada. Apuntes etnográficos de dos festivales de cine indígena en Colombia y Panamá". Revista Española de Antropología Americana 50: 265-276.

\section{Introducción}

En los últimos años hay una profusión de festivales de cine indígena en el mundo, especialmente en América y Oceanía. Dentro de la literatura antropológica se ha escrito sobre cine etnográfico (Piault 2002; Durington y Ruby 2011) y también sobre cine indígena (Ginsburg 2002; Salazar y Córdova 2008; Salazar 2016). Sin embargo, no ha sido hasta hace poco que se han empezado a analizar los festivales de cine etnográfico y, en menor medida, de cine indígena (Dowell 2006; Vallejo y Peirano 2017). La aproximación a estos últimos muestra unas formas de circulación e intercambio de imágenes, y da cuenta de unos modos de socialización a partir de unas relaciones de solidaridad, que escapan a las dinámicas propias del dualismo centro-periferia de los festivales de cine etnográfico, en los cuales se puede llegar a reproducir la "autoridad etnográfica" y la mirada externa. Los festivales de cine indígena desafían estas categorías de "alterización" (Peirano 2017: 33-34).

A partir de una aproximación etnográfica a dos festivales celebrados en el 2018 en comunidades indígenas (Daupará en Colombia y Jumara en Panamá), basada en las entrevistas con los cineastas y en la observación participante de los eventos, nuestro objetivo principal es hacer una aportación a los estudios de los festivales de cine indígena centrándonos en cómo se performa ${ }^{3}$ la indigeneidad. La constatación de las coincidencias y las diferencias de ambos festivales nos llevó a abordar este estudio comparativo. Si bien la elección de esas ediciones fue circunstancial, se articula a un proyecto de investigación colectivo sobre medios de comunicación indígena (http://mediosindigenas.ub.edu/).

La dimensión performativa de los festivales (qué se dice, qué se hace, cómo se ve el cine indígena), así como los criterios de aceptación de un determinado tipo de películas, contribuyen a delimitar lo que se entiende por indígena, lo cual supone unas definiciones en constante transformación. Por ejemplo, en el caso de Jumara, los criterios eran más flexibles ya que se aceptaban películas sobre temáticas indígenas hechas tanto por indígenas como por no indígenas, mientras que en Daupará existían dos categorías: una de realizadores indígenas y otra de colaboradores.

Los estudios sobre cine indígena, y los escasos sobre festivales de cine indígena, han hecho énfasis en las temáticas principales de las películas (relación con la naturaleza, cultura, derechos humanos) y su producción desde la perspectiva de la representación y la configuración de lo indígena (Córdova 2011; Mateus 2013; Mora 2015). Nuestro objetivo es contribuir a ese campo de análisis desde la distribución, la circulación y el consumo de las películas: lo que trataremos de argumentar es que

Si bien el sustantivo performance está contemplado como voz inglesa en el diccionario de la RAE (Real Academia Española), sus derivados (performada, performativa, etc.) no lo están. No obstante, en este texto los utilizamos con el objetivo de dar cuenta de la puesta en escena de unos procesos sociales cambiantes que hacen pertinente el uso de estos derivados. 
una etnografía de los festivales indígenas nos permite acercarnos a unas puestas en escena que, en última instancia, dan también cuenta de cómo se configura lo indígena en la actualidad.

Proponemos que estas puestas en escena tienen tres dimensiones. En primer lugar, constituyen una performance de lo indígena a través del cuerpo y la palabra, no sólo basada en una recreación del pasado, de la herencia, sino también en una invención hacia el futuro, lo cual implica una posibilidad de imaginarse como pueblos. En segundo lugar, muestran unas formas de organización interna que dan cuenta de un tejido social y político relacionado con linajes y liderazgos al interior de los grupos que organizan los festivales. $\mathrm{Y}$ en tercer lugar, revelan cómo lo indígena no sólo se entiende en relación a los territorios concretos de cada grupo, sino también a partir de unos intercambios y agendas políticas globales que dan cuenta de la indigeneidad en un contexto transnacional. Entendemos el concepto de indigeneidad, de acuerdo con De la Cadena y Starn (2009) y Jaramillo (2014), como una relación y una formación discursiva y no como una identidad esencial. Es decir, articulado con la formación de los estados nacionales, la relación con el espacio y una permanente transformación histórica. En este caso, nos interesa cómo se configura lo indígena a partir de la "apropiación" de los medios de comunicación.

Empezaremos con una contextualización analítica de las discusiones sobre cine indígena y festivales. Luego estudiaremos los ejemplos etnográficos de Daupará y Jumara. A continuación, plantearemos las diferencias y similitudes de los dos eventos en relación con las tres dimensiones antes mencionadas. Las consideraciones finales nos llevarán a reflexionar sobre la escenografía de lo indígena a partir del cuerpo y la palabra.

\section{Artefactos culturales, cosmopolítica y puesta en escena}

Los festivales de cine indígena han permitido que temas relacionados con lo indígena, como el cambio climático, la explotación económica de los recursos naturales, los rituales, la cultura material y las tradiciones, puedan circular más allá de los territorios propios. Esta posibilidad de circulación se vincula con la materialidad del objeto-película, en tanto artefacto cultural, que tiene unas características espaciales y temporales. Desde ciertas aproximaciones de la antropología visual se ha producido un "giro material" que ha hecho énfasis en los objetos visuales, situando su circulación como una forma de intercambio material (Edwards 2002; Banks 2010) y que trata de analizar las imágenes más allá de una perspectiva exclusivamente semiótica. Una aproximación a las películas indígenas, en tanto que artefactos culturales, implica tres características que parten de su materialidad: 1) son piezas nómadas que pueden deslocalizarse de su propio contexto geográfico, y más aún con los soportes digitales actuales. En este sentido, en Jumara y Daupará existía una organización en torno al sonido, los discos duros, los pendrive, los DVD, las pantallas, los ordenadores y todo lo que implica la materialidad que supone la proyección de películas; 2) son contenedores de tiempo, es decir que pueden volver al pasado a través de las historias que narran, y al mismo tiempo su visualización implica una temporalidad, y 3) son sociales, es decir que pueden visionarse colectivamente en cine-foros, festivales y encuentros (Gómez Ruiz 2018). Esta última característica lleva a que los festivales de cine indígena deban ser entendidos como "reuniones sociales que constituyen 
comunidades particulares, (y) crean regímenes de valor" (Ginsburg 2017: xv), lo cual implica subrayar la doble dimensión del cine indígena, en la pantalla (onscreen, en relación con las historias contadas en las películas) y fuera de ella (offscreen, en relación con su rol social al posibilitar en los festivales nuevas formas de solidaridad, identidad y comunidad) (Dowell 2006).

La dimensión material y nómada de las películas indígenas se vincula con un surgimiento cada vez más creciente de comunicadores indígenas cosmopolitas que viajan a festivales en el mundo, a la par que organizan festivales en sus comunidades, y que plantean unas agendas políticas por medio de la creación de redes transnacionales y espacios democráticos que van más allá de la relación con los estados (Graeber 2008; Hodgson 2008; Werbner 2008). En los festivales de cine indígena, los objetos-películas cobran una agencia propia e interpelan a las audiencias, permitiendo intercambios y diálogos entre realizadores, productores, distribuidores y públicos.

La puesta en escena que se da en los festivales de cine indígena hace uso de objetos, de imágenes que se intercambian y de ideas que se materializan en video-producciones. Instaura una temporalidad ritual que se dedica al visionado de películas como acto performativo y comunitario que comparte un mismo espacio. Los festivales de cine indígena, entendidos como ritual, disponen de unos tiempos y espacios que configuran unos modos de ver (Grasseni 2011) y al mismo tiempo muestran unos liderazgos y linajes determinados. El uso de la palabra y de las imágenes guía los planteamientos que se van dando al poner en la mesa temas comunes. En este sentido, las películas son un dispositivo que detona las palabras y las acciones (danzas, música, etc.), y les dan un lugar. Se trata de un ejercicio que hace referencia a la intimidad cultural, pero que al mismo tiempo tiene implicaciones en el fortalecimiento de los propios procesos de comunicación. Los festivales de cine indígena son una forma de acción, una cosmopolítica que actúa en el mundo desde la representación, pero también desde un hacer y un ver.

Así pues, los festivales de cine indígena pueden ser concebidos como escenarios creativos en los que, a través de la performance, se nos aparece con toda su fuerza la capacidad de las sociedades para expresar sus narrativas, sus paradigmas y sus símbolos culturales (Bruner 1993: 321).

La performance implica una teatralización de los dramas sociales, en términos de Victor Turner (1982); es decir, es una acto que representa la vida social desde un proceso de creación en el que la tradición puede ocupar un lugar relevante (Rosaldo et al. 1993: 5).

De esta manera, igual que el cine indígena puede ser entendido como un acto comunicativo de carácter poético, a partir de la definición de poesía, palabra proveniente del término griego poiesis, como una "acción creativa" (Salazar y Córdova 2008: 40), también los festivales de cine indígena pueden ser estudiados desde esta mirada poética, en tanto implican un proceso de invención.

El cine indígena constituye un vehículo de reproducción y transformación cultural en la medida que muestra interpretaciones de la relación con la tierra, la cosmología, el ritual, las amenazas a la lengua y la cultura, etc. (Ginsburg 1995). En los festivales de cine indígena, las características performativas que adquiere el visionado, se convierten en otro ámbito privilegiado de análisis de esa reproducción y transformación cultural. 


\section{Daupará y Jumara: la puesta en escena de la palabra y el cuerpo}

Los ejemplos etnográficos de Daupará y Jumara nos permitirán centrarnos en la circulación y consumo de cine en festivales y acercarnos a las formas performativas que se dan en estos eventos que se caracterizan por desarrollarse en comunidades indígenas.

\subsection{Daupará: el poder de ver más allá}

En el 2009 nació el Festival de Cine Indígena Daupará en Colombia. La palabra Daupará significa la capacidad que tienen los jaibaná (sabedores emberá) para conocer el mundo. Daupará se traduce como "el poder de ver más allá". La idea del festival se originó en el 2008 durante las movilizaciones en el Cauca, en las que se consolidó una agenda política para enfrentar el modelo de desarrollo económico "neoliberal y extractivista". Para esto, se buscaba tener un festival propio en el que los pueblos indígenas pudieran mostrar sus realizaciones audiovisuales. De esta forma, diferentes personas y organizaciones cercanas al movimiento indígena, como la Organización Nacional Indígena de Colombia (ONIC) y la Coordinadora Latinoamericana de Cine y Comunicación de los Pueblos Indígenas (CLACPI), manifestaron la necesidad de crear un espacio de difusión de las video-producciones indígenas (Villanueva y Guerrero 2013: 49-51). Daupará lleva más de diez ediciones en las que se intercala una presentación en Bogotá y otra en diferentes regiones de Colombia. Para los fundadores, no sólo se trata de un festival de cine indígena, sino que permite un encuentro de saberes en torno a la comunicación audiovisual, abordando distintas temáticas relacionadas con los medios indígenas como la auto-representación, la propiedad colectiva y las soberanías visuales. Se trata de una estrategia que además de ser una forma de resistencia indígena, se constituye como un medio central en la creación de redes y la consolidación de agendas políticas, y que es sobre todo un espacio de nuevas formas de sociabilidad y creación de lo indígena.

El X Festival de Cine y Video indígena Daupará, Los espiritus de la imagen, de 2018, tenía como anfitrión a tres de los cuatro pueblos indígenas de la Sierra Nevada de Santa Marta (arhuacos, wiwas y kankuamos). El festival consistía en un recorrido que empezaba en la ciudad de Santa Marta, y que luego viajaba por diferentes asentamientos. Entre los participantes del festival se encontraban varios realizadores indígenas del ya disuelto Colectivo de Comunicaciones Zhigoneshi, como el realizador arhuaco Amado Villafaña.

En los visionados de las películas, los niños se ubicaban en las primeras filas y los adultos en las de atrás. Las mujeres generalmente tejían mochilas y los hombres "poporeaban" ". Los niños más grandes traducían a los más pequeños del castellano al iku lo que se decía en las películas. La risa y los silencios eran un termómetro para ver cómo eran recibidas las películas, especialmente cuando veían a alguien conocido en la pantalla o ellos mismos eran representados. En ocasiones, el mamo (autoridad religiosa) se paraba y explicaba temas relacionados con los cantos y los bailes que eran representados. Al final del visionado de las películas se discutían

4 El poporo es un objeto de uso ceremonial y cotidiano exclusivo de los hombres. Está hecho de calabazo, cal, madera y fibra vegetal, y es usado en la Sierra Nevada para mascar ayu (hoja de coca). 
temas del orden más político en los que los realizadores indígenas tomaban la palabra.

Uno de los visionados fue la película Ranchería (2017) de Amado Villafaña, producida por la embajada suiza de Colombia. Las dinámicas y discusiones que se dieron en torno a esta obra dan cuenta de cómo se performa lo indígena y al mismo tiempo se crean redes de acción política pluriétnica. Su presentación en el festival se dio en el asentamiento wiwa de Gotshezhi. La pantalla se situó en una choza llamada uguma, que es un lugar de reunión tradicional de la comunidad wiwa. Amado Villafaña empezó su presentación hablando sobre la resistencia que han llevado a cabo los cuatro pueblos indígenas de la Sierra Nevada en la denominada Línea Negra ${ }^{5}$, el papel en la defensa del territorio, el cuidado del agua y la amenaza inminente que representan los proyectos de explotación minero-energéticos en los territorios indígenas, no sólo en la Sierra Nevada, sino en toda Colombia. La película trata sobre un pagamento (rito) de un mamo wiwa que viaja con un niño aprendiz y una $\operatorname{saga}^{6}$, desde donde nace el río Ranchería en territorio wiwa, hasta donde desemboca en territorio wayúu. En su travesía pasan por las minas de la empresa Cerrejón, mostrando la devastación ecológica de la compañía, y de paso el significado del agua para los wiwa, y lo que implicaría su desviación. Según el mamo, sería como tapar las vías de escape del pene. El documental termina con el testimonio de una mujer wayúu que dice que el gobierno colombiano les dio las mejores tierras a las empresas de explotación carbonífera, lo que ha implicado que el pueblo wayúu se esté muriendo de hambre y sed.

Después de la presentación de la película, intervino uno de los miembros del Colectivo de Comunicaciones Wayúu Putchamaajana (CCWP), señalando cómo finalmente se logró parar la desviación del río Ranchería. Este proceso significó un triunfo de la movilización no sólo de los pueblos indígenas del norte de Colombia, ya que contaron con la solidaridad de otros colectivos no indígenas de todo el país. El logro del pueblo wayúu implicó, según él, un periodo de persecuciones de los líderes indígenas por parte de la empresa Cerrejón. El documental destaca por su componente multiétnico: es dirigido por un arhuaco, trata sobre un pagamento wiwa y aborda la problemática nacional sobre la escasez de agua y alimento en territorio wayúu en la Guajira.

\subsection{Jumara: cine y cuerpo en movimiento}

En julio de 2018 se desarrolló en Piriatí Emberá, una comunidad situada en la Cuenca del Lago Bayano, la primera edición del Festival Internacional de Cine Indígena Jumara (vocablo emberá que significa "todos"). El evento surgió de la iniciativa de Iván Jaripio, joven cineasta emberá nacido en Piriatí, hijo del que fue el primer cacique del Congreso General Emberá del Alto Bayano. Tras participar en algunos

\footnotetext{
5 La Línea Negra comprende los resguardos arhaucos, kankuamos y kogi-malayo-arhaucos. Sin embargo, este territorio implica un espacio más amplio que los resguardos, no sólo geográficamente, sino dentro de las nociones propias de territorio. En 2018, en el decreto 1500, el Estado colombiano reconoce las fronteras de la Línea Negra, que engloba lugares sagrados para los indígenas.

6 Los mamos son agentes que median entre el mundo espiritual y el mundo material. Son guías de su comunidad y en torno a ellos se generan unas formas de organización social básica. Los mamos son hombres, pero entre los wiwa existe la figura femenina de la saga, que tiene características similares al mamo.
} 
talleres de capacitación cinematográfica, Iván realizó algunos cortometrajes que concursaron en festivales de diversas ciudades del mundo, en algunos de los cuales cosecharon premios. Tras estas experiencias, sintió la necesidad de realizar un festival de cine en una comunidad indígena, y qué mejor lugar que en la suya propia.

El festival contó con la ayuda organizativa y el patrocinio de entidades nacionales como Mente Pública, dedicada a fomentar proyectos de cine comunitario o popular indígena y no indígena, el Grupo Experimental de Cine Universitario (GECU) de la Universidad de Panamá y Acampadoc, organización orientada a la capacitación de jóvenes en cine documental. A un nivel internacional, colaboró la entidad canadiense Wapikoni Mobile, dedicada a la formación de cineastas indígenas.

En la mayoría de sesiones el público era relativamente escaso, entre diez y quince personas, con excepción de algunas a las que asistieron, acompañados por sus maestros, los alumnos de la escuela, y los actos de inauguración y clausura que fueron verdaderamente multitudinarios, con la asistencia de prácticamente todos los habitantes de la localidad.

Durante cuatro días fueron proyectándose en la Casa Comunal de Piriatí Emberá unos relatos visuales que propiciaron un acontecimiento particular en el que, también de forma visual y performativa, se mostraba con carácter festivo la cultura emberá. $\mathrm{Y}$ es que el festival fue vivido, sobre todo en los actos de inauguración y clausura, como una celebración. Además de los parlamentos de Iván y del cacique local, que trataron sobre la necesidad de contar las propias historias y de visionar otras historias indígenas, así como sobre la necesidad de luchar por la supervivencia cultural a partir de la reivindicación territorial ${ }^{7}$ y el mantenimiento de las tradiciones, hubo espectáculos de música y danza seguidos con emoción de manera participativa. La gente acudía con las vestimentas tradicionales (en el caso de las mujeres, un corpiño de aros metálicos que se añadía a la paruma, falda estampada usada cotidianamente; y en el de los hombres, un guayuco (calzoncillo) de tela o una falda de chaquiras), y con las pinturas corporales hechas con el tinte del fruto llamado jagua (genipa americana), que son uno de los máximos emblemas étnicos del grupo.

En el tiempo del festival se desarrolló una verdadera performance de la identidad propia. La creatividad emberá se observa en la misma obra cinematográfica de Iván Jaripio, por ejemplo en Identidad (2016), una hermosa metáfora sobre la pérdida de la cultura y la destrucción de la naturaleza y su reflejo en la desaparición de las pinturas de un cuerpo femenino. Este "cortometraje experimental", además de otros cortometrajes filmados en la zona, fueron exhibidos en la noche de clausura junto con otras películas, y fueron seguidos con especial atención y alegría por las gentes de la comunidad.

En Piriatí Emberá la pantalla mostró un conjunto de películas, procedentes de distintos países latinoamericanos, que trataban sobre la salvaguarda del territorio ante la amenaza del Estado y las empresas capitalistas, la necesidad de preservación de la cultura y la defensa de los derechos humanos ante las injusticias y la violencia. Las escenificaciones audiovisuales indígenas que se representaban en la pantalla de la Casa Comunal fueron el detonante de esta otra escenificación, en la que los emberá de Piriatí pusieron en movimiento sus tradiciones.

La titulación colectiva de los territorios habitados es la principal reivindicación de los emberá. 


\subsection{Linajes, alianzas y performance}

Dentro de los festivales de Daupará y Jumara, se pueden identificar algunos elementos comunes relacionados con: 1) la configuración de los liderazgos locales, 2) la importancia que tienen las alianzas transnacionales y nacionales, y 3) los temas que tratan las películas que hacen referencia a la defensa de la cultura y del territorio y a la amenaza que suponen distintos megaproyectos en los contextos locales. Igualmente, se pueden establecer algunas diferencias entre estos dos festivales, relacionadas con: a) el lugar que ocupa la colaboración interétnica entre los grupos que los organizan, y b) la manera en que se performa lo indígena.

En ambos eventos se pueden identificar unos linajes y liderazgos que tenían cierto protagonismo en la organización. En Jumara destaca el surgimiento, o quizás la continuación del linaje del joven Iván Jaripio, hijo de un destacado líder emberá. La formación en Panamá de unos liderazgos grupales emberá tiene que ver con la reivindicación de derechos territoriales iniciada en el Darién en la década de 1960 en el contexto de la competencia por la tierra con campesinos colonos, e intensificada con el apoyo del régimen de Omar Torrijos (Herlihy 1986; Colin 2010). La figura de Iván se articula con una nueva generación de activistas y jóvenes comunicadores que, por medio de la producción de cortometrajes y la organización de festivales, se han convertido en portavoces de la realidad de sus comunidades. En el caso de Daupará destaca el rol de Amado Villafaña, un hombre mayor que es líder de su comunidad y, como él mismo señala, una autoridad sobre temas de la imagen y el cine arhuaco. Él fue uno de los principales responsables de la logística del festival, especialmente en relación con la presentación de películas y con la comunicación con los diferentes asentamientos de la Sierra Nevada. Amado es hijo de Duane Villafaña, un líder indígena que en 1916 encabezó la primera comisión de arhuacos para hablar con el presidente de Colombia sobre la presencia de los capuchinos en la Sierra Nevada. En efecto, los linajes (tana) organizados a partir de una herencia patrilineal y un tipo de asentamiento matrilocal, son muy importantes en la organización social del pueblo arhuaco. Esto se puede reconocer en el hecho de que los apellidos de los integrantes de la citada comisión de 1916 se mantengan en los tana de las mujeres y los hombres líderes actuales: Villafaña, Izquierdo, Fermín, Garavito, Torres y Mejía.

De acuerdo con Clastres (2001) la importancia de los "jefes primitivos" está en aparecer cuando es necesario ponerse en comunicación con otras sociedades. Este rol se mantiene e incluso se intensifica en la era actual de la tecnología audiovisual, ya que como muestra Terence Turner (1992: 6-7) para el caso kayapó en Brasil, la filmación y edición de videos o películas adquiere una especial significación social y política a partir del prestigio que tales actividades confieren y del hecho de que constituyan una importante forma de mediación con el mundo occidental.

Por otra parte, los dos festivales comparten la creación de alianzas locales y trasnacionales con actores no indígenas. En el caso de Jumara, la organización contó con una red nacional e internacional que incluye las organizaciones sin ánimo de lucro y plataformas universitarias ya citadas. Se trata de unos aliados estratégicos no solamente en la creación y financiación concreta de Jumara (y en la formación de Iván Jaripio y otros cineastas emberá), sino en la conformación de un tejido más amplio de dimensiones nacionales y continentales responsable de la organización de festivales y talleres de capacitación. En el caso de Daupará, la organización del festival contó con diferentes aliados nacionales como la ANTV (Autoridad Nacional de 
Televisión), con la cual estaba financiando unos programas de la serie El Buen Vivir, el Ministerio de Cultura de Colombia y la ONIC, entre otros. Así mismo contó con investigadores, antropólogos y comunicadores no indígenas que venían de Bogotá y otras partes del mundo.

Una de las divergencias entre ambos festivales, se encuentra en la forma de establecer colaboraciones interétnicas. Mientras que en Jumara la organización se dio casi exclusivamente con los emberá y panameños no indígenas, en el caso de Daupará se contó con la presencia de varios grupos indígenas de Colombia. En la organización del festival participaron los pueblos de la Sierra Nevada como los wiwa, los arhuaco, los kankuamo y los wayúu (que no son propiamente de la Sierra, pero se encuentran al norte de ésta). En particular, hay que destacar el Colectivo Arhauco Yosokwi, el Colectivo Wiwa Bukuaneyuman y la Red de Comunicación del pueblo Wayúu Puntchimajana, además del cabildo indígena y la Confederación Indígena Tayrona (CIT). Por otra parte, había comunicadores de toda Colombia: de los pueblos indígenas nasa, emberá, kuna y representantes de las comunidades afrocolombianas. Esta presencia multiétnica, en el caso colombiano, se relaciona con la lucha indígena que se ha dado con el apoyo de organizaciones como la ONIC, el Consejo Regional Indigena del Cauca (CRIC) y la CIT, que han jugado un papel fundamental en la consolidación de la agenda comunicativa indígena a nivel nacional por medio de la Mesa de Concertación Nacional, la cual ha permitido consolidar eventos como el festival Daupará.

La otra diferencia destacable tiene que ver con una mayor preponderancia del cuerpo o la palabra en uno u otro festival. En Jumara se muestra una puesta en escena en la que el cuerpo y su ornamentación (las danzas, las vestimentas, las pinturas) cobran un protagonismo especial. Esta escenografía, en la que se recrean tradiciones, responde a una firme voluntad de mantener, a través de su actuación, la cultura y el patrimonio. La dimensión performativa debe ser pues entendida como la voluntad de afirmación étnica de una sociedad preocupada por la autonomía de sus territorios y la pervivencia de su cultura. En el caso de Daupará, si bien los participantes usaban la manta blanca tradicional, la mochila y el poporo que hacen parte de su cotidianidad, se privilegió más la palabra como una forma de performar lo indígena. Al finalizar las proyecciones, los realizadores discutían sobre los problemas de fondo que trataban en sus producciones. El visionado de películas permitía establecer un espacio para acordar estrategias de resistencia y organización para afrontar los problemas que estaban viviendo como pueblos indígenas en diferentes partes del territorio nacional, relacionados generalmente con los proyectos extractivistas en torno a la minería, el carbón y las hidroeléctricas.

\section{A manera de conclusión}

Los festivales de cine indígena son un espacio de distribución de las producciones recientes de los realizadores y comunicadores, que se han ido configurando por medio de unas luchas históricas en torno a la auto-representación y la soberanía visual. También son un espacio de socialización en el que unos liderazgos determinados asumen un papel preponderante, así como de creación de redes nacionales y trasnacionales que fortalecen las luchas que se dan en el territorio. Pero especialmente, son espacios escenográficos en los que se performa la indigeneidad, y que en última instancia tienen 
una connotación ritual y política. Por un lado, los festivales muestran rituales y prácticas culturales de los pueblos que se representan en las películas, y son rituales en sí mismos al convertirse en ceremonias en las que se genera un diálogo entre las películas y los públicos a través del cuerpo y la palabra. Y, por otro lado, permiten aproximarse a las distintas estrategias de organización y discusión política en torno a la autonomía, la comunicación y las amenazas actuales de etnocidio y ecocidio.

Estas argumentaciones hubieran sido imposibles sin la aproximación etnográfica a ambos eventos, lo cual implica no sólo abordar lo que presentan las películas, sino también lo que ocurre en el campo. En efecto, sin este trabajo sobre el terreno no sería posible analizar cómo se (re)configura lo indígena. Tanto las diferencias como las similitudes de estos dos contextos etnográficos, permiten aproximarse a las estrategias que utilizan los pueblos indígenas para dar cuenta de sus producciones audiovisuales, pero especialmente a las relaciones sociales que se establecen paralelamente a las proyecciones. Es decir, que en términos metodológicos, más allá del análisis del cine indígena centrado en las películas en tanto vehículos de representación, existe un entramado social y político que abarca las experiencias y puestas en escena que se dan en los festivales con todas sus relaciones, materialidades y corporalidades.

\section{Referencias}

Banks, Marcus. 2010. Los datos visuales en la investigación cualitativa. Madrid: Morata. Bruner, Edward M. 1993. «Epilogue: Creative Persona and the Problem of Authenticity», en Creativity/Anthropology, Smadar Lavie, Kirin Narayan y Renato Rosaldo, eds., pp. 321-334. Ithaca y Londres: Cornell University Press. https://doi.org/10.7591/9781501726033-015.

Clastres, Pierre. 2001. Investigaciones en Antropología Política. Barcelona: Editorial Gedisa. Colin, France-Lise. 2010. Nosotros no solamente podemos vivir de cultura: Identity, Nature and Power in the Comarca Emberá of Eastern Panama. Tesis doctoral. Department of Geography and Environmental Studies, Carleton University, Ottawa.

Córdova, Amalia. 2011. «Estéticas enraizadas: aproximaciones al vídeo indígena en América Latina». Comunicación y medios 24: 81-107. https://comunicacionymedios.uchile.cl/ index.php/RCM/article/view/19895

Dela Cadena, Marisoly Orin Starn. 2009. «Indigeneidad:problemáticas, experienciasy agendas en el nuevo milenio». Tabula Rasa 10: 191-223. https://doi.org/10.25058/20112742.359.

Dowell, Kristin. 2006. «Indigenous Media Gone Global: Strengthening Indigenous Identity On and Offscreen at the First Nations/First Features Film Showcase». American Anthropologist 108 (2): 376-384. https://doi.org/10.1525/aa.2006.108.2.376.

Durington, Matthew y Jay Ruby. 2011. «Ethnographic film», en Made to be Seen: Perspectives on the History of Visual Anthropology, Marcus Banks y Jay Ruby, eds., pp. 190-208. Chicago: University of Chicago Press.

Edwards, Elizabeth. 2002. «Material Beings: Objecthood and Ethnographic Photographs». Visual Studies 17 (1): 67-75. https://doi.org/10.1080/14725860220137336.

Ginsburg, Faye. 1995. «Production Values: Indigenous Media and the Rhetoric of Self-Determination», en Rhetorics of Self-making, Debbora Battaglia, ed., pp. 121-138. Berkeley y Los Angeles: University of California Press.

-. 2002. «Mediating Culture: Indigenous Media, Ethnographic Film and the Production of Identity», en The Anthropology of Media: A Reader, Kelly Askew y Richard R. Wilk, eds., pp. 210-235. Oxford: Blackwell Publishers. 
- 2017. «Preface. Screening Anthropology across the Planet», en Film Festivals and Anthropology, Aída Vallejo y María Paz Peirano, eds., pp. xiii-xvi. Newcastle upon Tyne: Cambridge Scholars Publishing.

Gómez Ruiz, Sebastián. 2018. «Imágenes de la Sierra Nevada (Colombia): el artefacto cultural como una manera para aproximarse a los medios de comunicación indígena», en Culturas indígenas: investigación, comunicación y resistencias, Amparo Huertas Bailén y María Luna, eds., pp. 197-219. Bellaterra: InCom-UAB.

Graeber, David. 2008. «On Cosmpolitanism and (Vernacular) Democratic Creativity: Or, There Never Was a West», en Anthropology and the New Cosmopolitanism. Rooted, Feminist and Vernacular Perspectives, Pnina Werbner, ed., pp. 281-306. Nueva York: Berg. https://doi.org/10.5040/9781474214186.ch-014.

Grasseni, Cristina. 2011. «Skilled Visions: Toward an Ecology of Visual Inscriptions», en Made to Be Seen: Perspectives on the History of Visual Anthropology, Marcus Banks y Jay Ruby, ed., pp. 19-44. Chicago y Londres: The University of Chicago Press.

Herlihy, Peter H. 1986. A Cultural Geography of the Embera and Wounan (Choco) Indians of Darien, Panama, with Emphasis on Recent village Formation and Economic Diversification. Tesis doctoral. Department of Geography and Anthropology, Louisiana State University, Baton Rouge.

Hodgson, Dorothy L. 2008. «Cosmopolitics, Neoliberalism, and the State: The Indigenous Rights Movement in Africa», en Anthropology and the New Cosmopolitanism. Rooted, Feminist and Vernacular Perspectives, Pnina Werbner, ed., pp. 215-230. Nueva York: Berg. https://doi.org/10.5040/9781474214186.ch-011.

Jaramillo, Pablo. 2014. Etnicidad y victimización. Genealogías de la violencia y la indigenidad en el norte de Colombia. Bogotá: Ediciones Uniandes.

Mateus, Angélica. 2013. El indígena en el cine y el audiovisual colombianos: imágenes y conflictos. Medellín: La Carreta Editores.

Mora, Pablo, ed. 2015. Poéticas de la resistencia. El video indígena en Colombia. Bogotá: Cinemateca Distrital-IDARTES.

Peirano, María Paz. 2017. «Part I. Introduction. Mapping Ethnographic Film Festivals», en Film Festivals and Anthropology, Aída Vallejo y María Paz Peirano, eds., pp. 21-36. Newcastle upon Tyne: Cambridge Scholars Publishing.

Piault, Marc Henri. 2002. Antropología y cine. Madrid: Cátedra.

Rosaldo, Renato, Smadar Lavie y Kirin Narayan. 1993. «Introduction: Creativity in Anthropology», en Creativity/Anthropology, Smadar Lavie, Kirin Narayan y Renato Rosaldo, eds., pp. 1-8. Ithaca y Londres: Cornell University Press. https://doi.org/10.7591/9781501726033-001.

Salazar, Juan Francisco. 2016. «Contar para ser contados: el vídeo indígena como práctica ciudadana», en Miradas propias. Pueblos indígenas, comunicación y medios en la sociedad global, Claudia Magallanes Blanco y José Manuel Ramos Rodríguez, coords., pp. 91-109. Puebla: Universidad Iberoamericana-CIESPAL.

Salazar, Juan Francisco y Amalia Córdova. 2008. «Imperfect Media and the Poetics of Indigenous Video in Latin America», en Global Indigenous Media: Cultures, Poetics, and Politics, Pamela Wilson y Michelle Stewart, eds., pp. 39-57. Durham y Londres: Duke University Press.

Turner, Terence. 1992. «Defiant Images: The Kayapo Appropriation of Video». Anthropology Today 8 (6): 5-16. https://doi.org/10.2307/2783265.

Turner, Victor. 1982. From Ritual to Theatre. The Human Seriousness of Play. Nueva York: PAJ Publications. 
Vallejo, Aída y María Paz Peirano, eds. 2017. Film Festivals and Anthropology. Newcastle upon Tyne: Cambridge Scholars Publishing.

Villanueva, Rosaura y María Angélica Guerrero. 2013. «Para ver más allá. Reseña Histórica de Daupará», en Daupará. Muestra de cine y video de los pueblos indígenas de Colombia, Pablo Mora, ed., pp. 49-63. Bogotá: IDARTES.

Werbner, Pnina. 2008. «Introduction: Towards a New Cosmopolitan Anthropology», en Anthropology and the New Cosmopolitanism. Rooted, Feminist and Vernacular Perspectives, Pnina Werbner, ed., pp. 1-29. Nueva York: Berg. https://doi.org/10.5040/9781474214186.ch-001. 